\title{
Roles of CREB-binding protein (CBP)/p300 in respiratory epithelium tumorigenesis
}

\author{
Michalis V Karamouzis ${ }^{1}$, Panagiotis A Konstantinopoulos ${ }^{1,2}$, Athanasios G Papavassiliou ${ }^{1}$ \\ ${ }^{1}$ Department of Biological Chemistry, Medical School, University of Athens, 75, M Asias Street, 11527 Athens, Greece; ${ }^{2}$ Division of \\ Hematology-Oncology, Beth Israel Deaconess Medical Center, Harvard Medical School, Boston, MA 02215, USA
}

CREB-binding protein (CBP) and its homologue p300 are transcriptional co-activators of various sequence-specific transcription factors that are involved in a wide array of cellular activities, such as DNA repair, cell growth, differentiation and apoptosis. Several studies have suggested that CBP and p300 might be considered as tumour suppressors, with their prominent role being the cross-coupling of distinct gene expression patterns in response to various stimuli. They exert their actions mainly via acetylation of histones and other regulatory proteins (e.g. p53). A major paradox in CBP/ p300 function is that they seem capable of contributing to various opposed cellular processes. Respiratory epithelium tumorigenesis represents a complex process of multi-step accumulations of a gamut of genetic and epigenetic aberrations. Transcription modulation through the alternate formation of activating and repressive complexes is the ultimate converging point of these derangements, and $\mathrm{CBP} / \mathrm{p} 300$ represents key participants in this interplay. Thus, illumination of their molecular actions and interactions could reveal new potential targets for pharmacological interventions in respiratory epithelium carcinogenesis.

Keywords: CBP, p300, lung cancer, acetylation, transcription factor

Cell Research (2007) 17:324-332. doi: 10.1038/cr.2007.10; published online 20 March 2007

\section{Introduction}

cAMP response element-binding protein-binding protein (CBP) and p300 were originally identified as factors binding to the cAMP response element-binding protein (CREB) and the adenoviral E1A, respectively $[1,2]$. The human $C B P$ locus resides in the chromosomal region 16 p13.3 and shows homology to $22 \mathrm{q} 13$, where p300 is located [3]. CBP/p300 proteins share several conserved regions, which constitute most of their known functional domains (Figure 1). CBP and p300 have interchangeable roles during embryonic development and in many processes govern cellular homeostasis $[4,5]$. However, genetic and molecular evidence suggests that they also fulfil distinct functions [3]. Homozygous CBP-/- and p300-/- knockout mice were inviable due to severe developmental de-

Correspondence: Athanasios G Papavassiliou Tel: +30-210-7462509; Fax: +30-210-7791207

E-mail: papavas@med.uoa.gr fects, albeit abnormal heart formation was noted only in p300-/- mice, thus suggesting that both proteins are necessary during embryogenesis with overlapping and unique functions [6]. Consistently, double heterozygous $\mathrm{CBP}+/-$ and $\mathrm{p} 300+/-$ knockout mice are also embryonic lethal. However, only $\mathrm{CBP}+/-$ mice display features of Rubinstein-Taybi syndrome (RTS) [6, 7], while a more severe and penetrant RTS-like phenotype was found in mice in which one CBP allele was modified to express a truncated CBP protein [7].

Apart from other structurally defined regions, CBP/p300 have specific areas for interaction with a wide array of transcription factors and co-factors (Figure 1). The plethora of these interacting proteins indicates the unique involvement of $\mathrm{CBP} / \mathrm{p} 300$ in transcriptional control as ubiquitous and versatile co-integrators. Many of the protein interactions with $\mathrm{CBP} / \mathrm{p} 300$ are regulated by upstream signals. For example, phosphorylation of the transcription factor CREB modulates its interaction with CBP, while hormones can induce the binding of $\mathrm{CBP} / \mathrm{p} 300$ to nuclear receptors [8]. Notably, in some cases CBP/p300 can stimulate diverse 

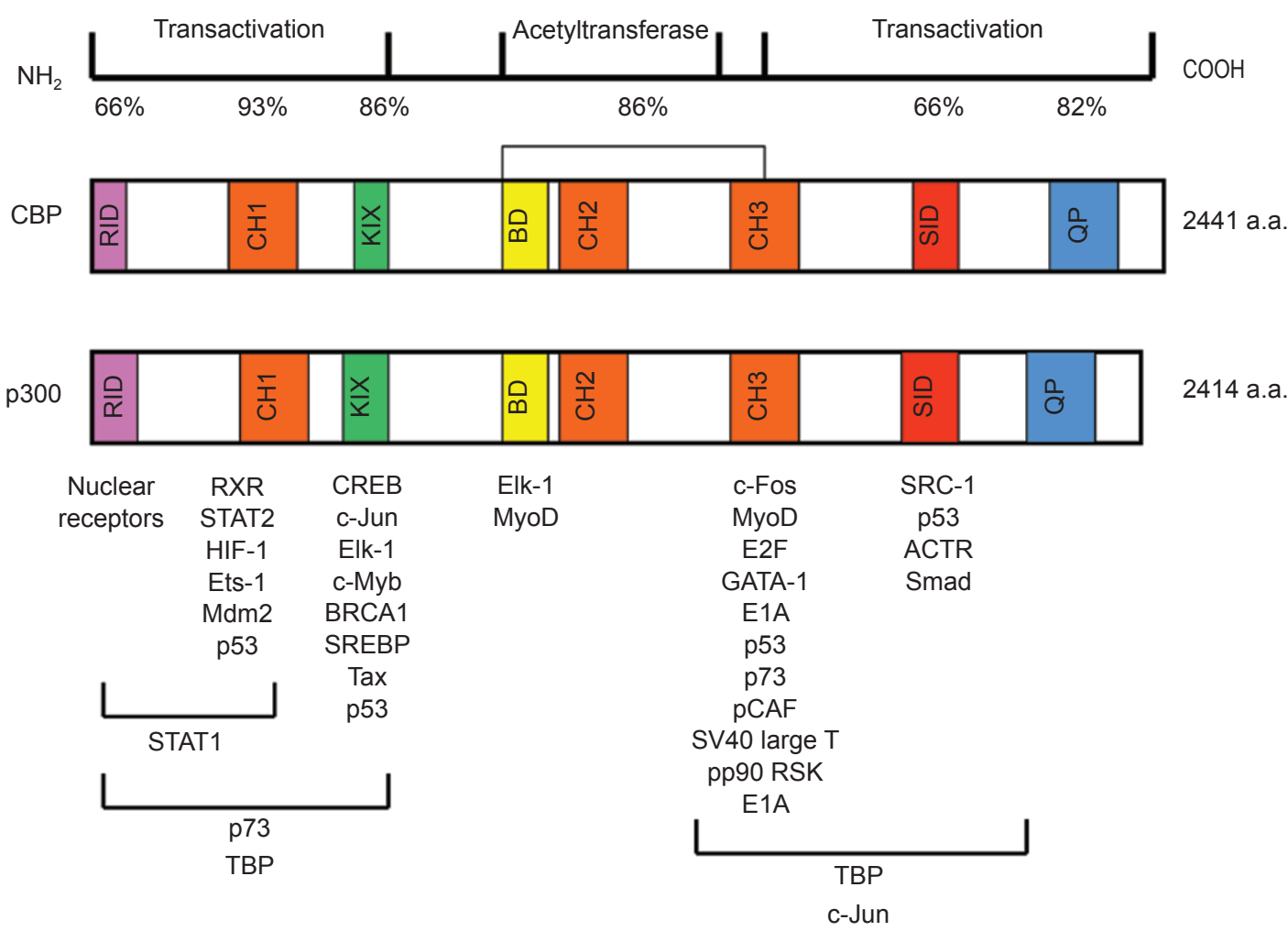

2414 a.a.

Figure 1 Schematic representation of CBP and p300 homologous regions and functional domains along with a selected list of proteins that bind to specific sites of $\mathrm{CBP} / \mathrm{p} 300$. BD, bromodomain; $\mathrm{CH} 1-3$, cysteine and histidine-rich regions 1-3; KIX, binding site of CREB; QP, glutamine- and proline-rich domain; RID, receptor-interacting domain; SID, steroid receptor co-activator-1 interaction domain.

functions of certain transcriptional regulatory proteins [4, 5]. Nevertheless, the most intriguing feature of $\mathrm{CBP} / \mathrm{p} 300$ is their stoichiometric function in vivo and their intrinsic enzymatic activities.

The importance of $\mathrm{CBP} / \mathrm{p} 300$ is underscored by the fact that genetic alterations as well as their functional dysregulation are strongly linked to human diseases. Germline mutations of $C B P$ were first reported in RTS, an autosomaldominant disease characterised by mental retardation, skeletal abnormalities and a high malignancy risk, albeit such defects have not been associated with p300 so far $[9,10]$. Nonetheless, mutations of the $p 300$ gene have been detected in human epithelial tumours, which is consistent with the general notion that $\mathrm{p} 300$ might possess tumour-suppressor activity $[11,12]$. Although the tumour-suppressor function of CBP is still unclear, its involvement in chromosomal translocations associated with haematologic malignancies has been well-documented [13]. The critical involvement of $\mathrm{CBP} / \mathrm{p} 300$ proteins in a variety of key molecular pathways provides the mechanistic rationale of their implication in respiratory epithelium tumorigenesis.

\section{CBP/p300 transcriptional activity}

The multifaceted role of $\mathrm{CBP} / \mathrm{p} 300$ in transcription can be achieved by various mechanisms (Figure 2). CBP/p300 are thought to serve as a physical "bridge" between diverse gene-specific transcription factors (GSTFs) and components of the basal transcriptional machinery (BTM; e.g. TATA box-binding protein, TFIIB, TFIIE, TFIIF) thereby stabilising the transcription complex [4]. CBP/p300 might also act as a scaffold for the formation of multi-component complexes containing transcription factors and co-factors. A classical example of complex assembly involving multiple transcription factors and co-factors is the $\beta$-interferon gene promoter in response to viral infections [14]. The large size of $\mathrm{CBP} / \mathrm{p} 300$ endows them with many different interaction surfaces, thus enabling them to bind concurrently to various proteins. By providing a platform for the assembly of transcription regulatory proteins, $\mathrm{CBP} / \mathrm{p} 300$ might increase the relative concentration of these factors in the local transcriptional environment (Figure 2). Accordingly, cells can cooperatively utilise its repertoire 


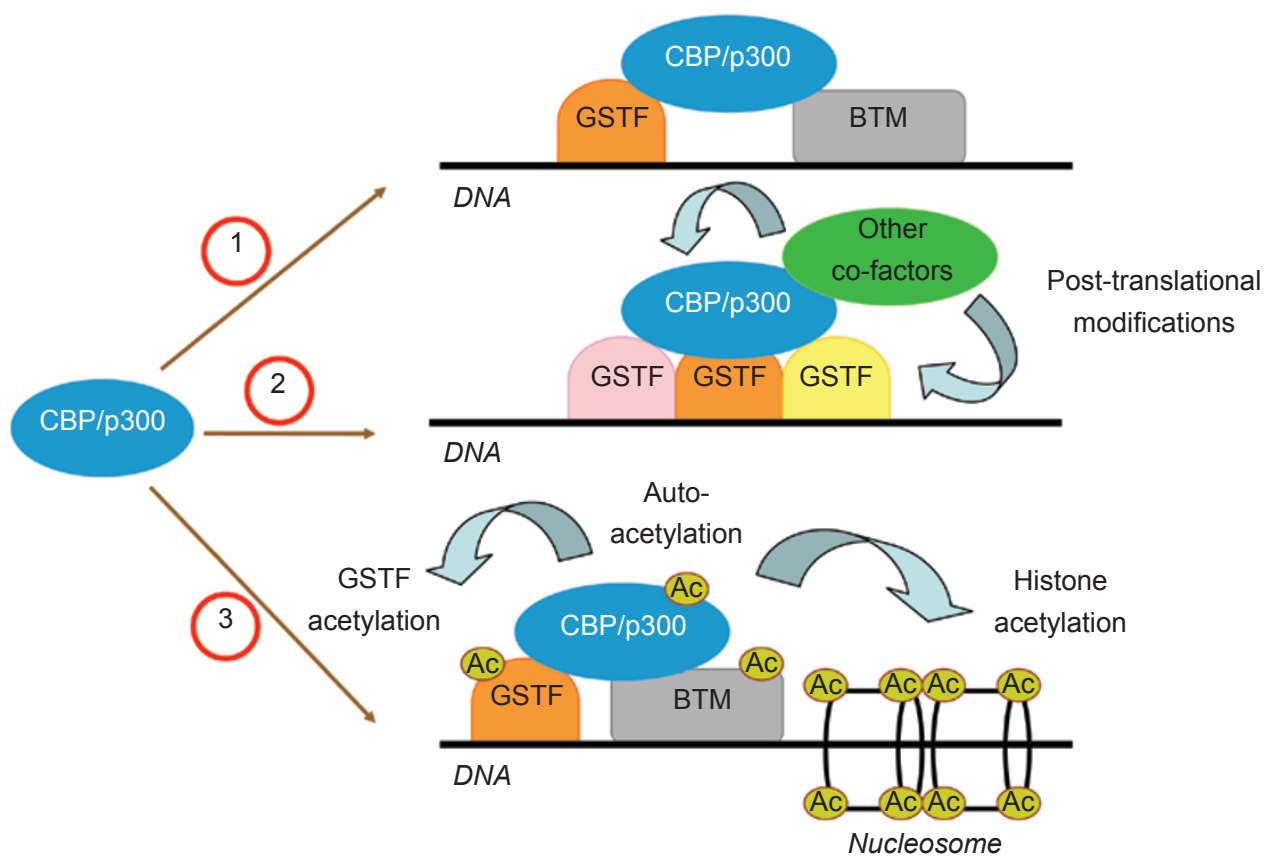

Figure $2 \mathrm{CBP} / \mathrm{p} 300$ participate in transcriptional control through various mechanisms. (1) "Bridging" GSTFs with the BTM. (2) Contributing to the formation of multi-protein complexes and directly and/or indirectly modulating the activation status of GSTFs through post-translational modifications. (3) Exhibiting acetyl-transferase activity on nucleosomes and certain GSTFs. Ac, acetyl group.

of proteins, so that the combinations of a few ubiquitous factors, and signal- and tissue-specific modulators, could create a broad spectrum of regulatory complexes.

Post-translational chromatin modifications modulate the activity of many genes by modifying both the core histones and non-histone transcription factors [15]. Acetylation of multiple sites in the histone tails has been directly associated with transcriptional upregulation, while de-acetylation correlates with transcriptional repression. Mechanistically, histone acetylation promotes the accessibility of DNA to transcription protein complexes, by facilitating the "unwiring" of the chromatin structure [16]. CBP/p300 can interact with chromatin nucleosomes via nucleosome assembly proteins, histone-binding proteins and possibly histones themselves $[17,18]$. In addition to histones, $\mathrm{CBP} / \mathrm{p} 300$ also modulate a variety of other proteins by acetylation $[19,20]$. In most instances, acetylation of transcription factors has been shown to enhance their DNA-binding activity (e.g. $\mathrm{p} 53$, p73, retinoblastoma $(\mathrm{Rb}), \mathrm{E} 2 \mathrm{~F}, \mathrm{Sp} 3$, signal transducers and activators of transcription) [11,21], although it seems plausible that acetylation also regulates protein-protein interactions, protein-DNA recognition [19], as well as nuclear transport and structure $[22,23]$. Acetylation of components of the BTM (e.g. TFIIE, TFIIF) has been found to enhance DNA-binding activity and gene transcription [24]. Moreover, CBP/p300 can bind additional co-factors that possess acetyl-transferase activity (e.g. p300/CBPassociated factor ( $\mathrm{p} / \mathrm{CAF})$ ) [25], and also recruit proteins bearing other chromatin-modifying enzymatic activities (e.g. histone methyltransferases) [26].

The ability of so many proteins to interact with $\mathrm{CBP} / \mathrm{p} 300$ suggests that competition for the rather limited intracellular pool of CBP/p300 might account for the observation that unrelated transcription factors inhibit each other without direct interference [27, 28]. In this vein, sequestration of $\mathrm{CBP} / \mathrm{p} 300$ by the adenoviral protein E1A [29], human papilloma virus protein E6 [30] and other viral proteins [3] is probably a means by which oncogenic viruses suppress many cellular transcription factors, and thereby may contribute to cellular transformation.

Given the multiple activities of $\mathrm{CBP} / \mathrm{p} 300$, it is of paramount importance to enlighten their own regulatory principles. $\mathrm{CBP} / \mathrm{p} 300$ are thought to be modulated by phosphorylation via cyclin/cyclin-dependent kinase (Cdk) complexes in $\mathrm{G}_{1} / \mathrm{S}$ [31], whereas various kinases, such as protein kinase $\mathrm{A}$, protein kinase $\mathrm{C}$, phosphatidylinositol-3 kinase/AKT and mitogen-activated protein kinases (MAPK), have been shown to phosphorylate CBP in vitro 
$[19,32]$. Furthermore, CBP/p300 are also targets of other post-translational modifications, such as methylation [33] and sumoylation [34]. Recent data have indicated the existence of an auto-regulatory loop, whereby the acetyltransferase activity of p 300 is considered to be intrinsically weak [35], and its auto-acetylation, or possibly acetylation via other proteins, might stimulate its acetyl-transferase activity [35]. De-acetylases (e.g. histone deacetylase 1 (HDAC1)) or other proteins (e.g. p53) could associate with p300 to keep it in a catalytically inactive state $[36,37]$. On the other hand, it has been shown that p300 can also inactivate HDAC1 via acetylation. Thus, two positive feedback loops (activation through auto-acetylation and inhibition of an inhibitor) ensure maximal p300 activity. A recent study has suggested that p300 auto-acetylation serves as a switch to regulate its arrival and departure during pre-initiation complex assembly [38]. In addition, there is evidence that p300 also functions in elongation [39]. Therefore, the activity of CBP and/or p300 and their capacity to bind with certain transcriptional regulatory proteins are subjected to regulation by diverse mechanisms, hence contributing to transcriptional specificity and plasticity.

\section{Implication of $\mathrm{CBP} / \mathrm{p300}$ in respiratory epithelium tumorigenesis}

Most of the described tumour-related mutations in CBP/ p300 result in truncation of the p300 protein. In majority of the cases, the second allele was inactivated through deletion (loss of heterozygosity (LOH)), silencing (hemizygosity) or a different mutation (compound heterozygosity). These findings have qualified p300 as a classical tumour-suppressor gene, but with a low detected mutation rate in cell lines [40]. It is currently less clear whether CBP should also be classified as a tumour-suppressor gene. However, the high prevalence of malignant tumours among RTS patients along with the fact that both CBP and p300 proteins are targets of transforming viruses suggest that disruption of CBP function contributes to carcinogenesis [11]. In lung cancer, $\mathrm{LOH}$ has been frequently detected in diverse chromosomal regions, albeit relatively few targeted tumour suppressor genes (including $p 53, R b, p 16$ and FHIT) have been identified [41]. Recently, it was shown that the $C B P$ gene is genetically altered in almost $15 \%$ of lung cancer cell lines and $5 \%$ of primary lung tumours [42]. Thus, point mutations and homozygous deletions of the $C B P$ gene might be involved in the pathogenesis of a subset of lung carcinomas (Figure 3). Interestingly enough, these $C B P$ mutations are not clustered in the catalytic (acetyltransferase) region but are dispersed throughout the entire gene, indicating that the biological effects of such mutations are diverse [42]. Another important aspect is the observed

\section{$\mathrm{CBP} / \mathrm{p} 300$ in lung carcinogenesis}

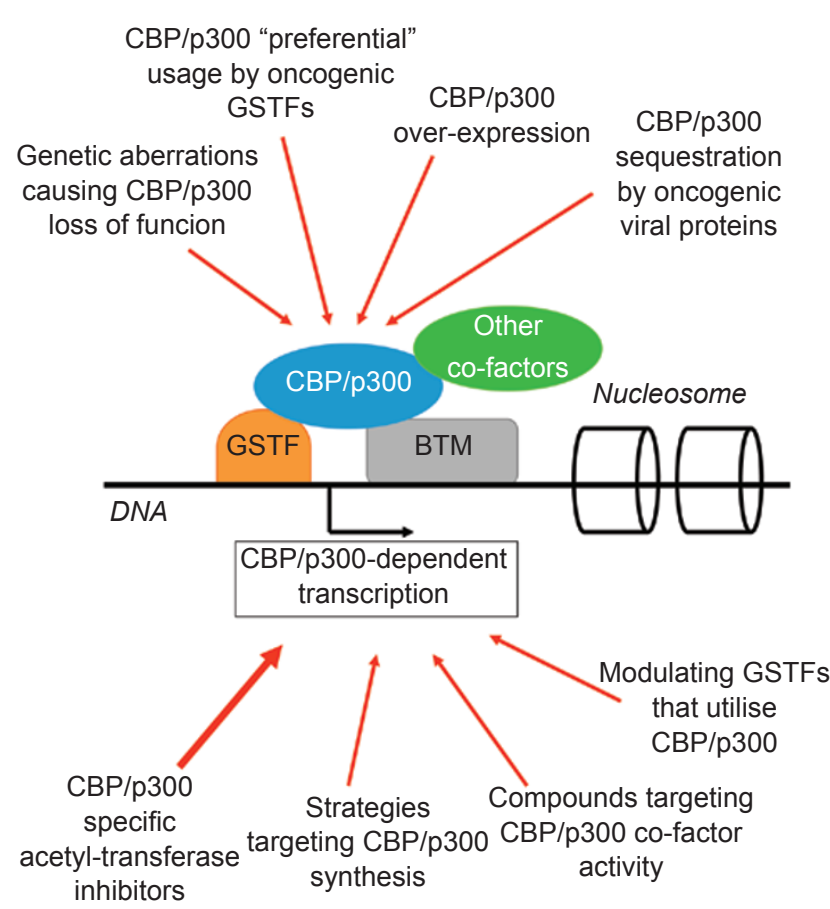

Potential therapeutic approaches

Figure $3 \mathrm{CBP} / \mathrm{p} 300$ may contribute to respiratory epithelium carcinogenesis via multiple routes. Potential strategies for therapeutic interventions are indicated (currently tested regimens mostly target CBP/p300 acetyl-transferase activity; thicker arrow). BTM, basal transcriptional machinery; GSTF, gene-specific transcription factor.

coexistence of $\mathrm{CBP}$ and $\mathrm{p} 53$ mutations, which suggests that $C B P$ gene alterations might contribute to lung carcinogenesis by distorting pathways other than those engaging $\mathrm{p} 53$. Regarding p300, somatic mutations have been identified in several types of cancers [43], but their prevalence in lung cancer is unknown. The notion that CBP and p300 might play different roles in diseases such as lung tumorigenesis is supported by the observation that reintroduction of $\mathrm{p} 300$ but not CBP was able to suppress the growth of p300-deficient carcinoma cells [44].

Since mutations in CBP/p300 are relatively uncommon, $\mathrm{CBP} / \mathrm{p} 300$ might contribute to lung carcinogenesis through alternative mechanisms (Figure 3). The cell-cycle apparatus acts as a dominant controller "supervising" the cell fate, and its deregulation represents an imperative step during malignant transformation. $\mathrm{CBP} / \mathrm{p} 300$ are shown to associate 
with the cyclin E/Cdk2 complex [45]. Although the precise role of $\mathrm{CBP} / \mathrm{p} 300$ in regulating cell proliferation remains elusive, existing evidence suggests that they are negative modulators of the cell cycle. The fact that these proteins are targets of viral oncoproteins also suggests their importance in cell-cycle regulation, such as the control of DNA synthesis and S-phase progression [46]. For example, it has been shown that the p300/CBP-p/CAF protein complex can arrest cell cycle and might regulate target genes that are involved in the control of the $\mathrm{G}_{1} / \mathrm{S}$ transition, such as $p 21$ [46]. In vitro models have also suggested that sequestration of $\mathrm{CBP} / \mathrm{p} 300$ by viral oncoproteins has the general effect of modulating transcription through affecting transcription factors that normally utilise these co-activators [46], while the recently recognised link between $\mathrm{CBP} / \mathrm{p} 300$ and the anaphase-promoting complex/cyclosomeE3 ubiquitin ligase has provided new insights into the roles of these proteins in the control of both cell cycle and transcription [45].

$\mathrm{CBP} / \mathrm{p} 300$ are cardinal transcriptional co-regulators responsible for the proper function of a gamut of signalling cascades. To this end, the growth-suppressing effect of $\mathrm{CBP} / \mathrm{p} 300$ might be well explained by their ability to augment p53-mediated transcription [47]. The $p 53$ tumour suppressor gene is the most commonly mutated gene in human cancers and is frequently found to be dysregulated in lung pre-malignant and malignant lesions [48]. A major function of $\mathrm{p} 53$ is to activate genes engaged in the response to DNA damage, such as murine double minute 2 ( $m d m 2)$, p21, cyclin D1 and Bax [47]. Following DNA damage, p53 is activated by kinase-mediated phosphorylation as well as by acetylation at specific residues by $\mathrm{CBP} / \mathrm{p} 300$ [49], resulting in increased stability of the $\mathrm{p} 53-\mathrm{CBP} / \mathrm{p} 300$ DNA complex. Furthermore, $\mathrm{CBP} / \mathrm{p} 300$ is required for p53-mediated transactivation of target genes through their co-activator function and through local histone acetylation [50]. It has also been suggested that the association of p53 with $\mathrm{CBP} / \mathrm{p} 300$ might account for p53-mediated negative regulation of genes whose promoters lack a suitable p53 binding site [51]. Interestingly, CBP/p300 also contribute to controlling p53 stability by regulating its ubiquitination and degradation, through both Mdm2-dependent and Mdm2-independent mechanisms. Degradation of p53 is known to be mediated by a ternary complex comprising p53, Mdm2 and CBP/p300 [52]. Recently, the CH1 domain of $\mathrm{CBP} / \mathrm{p} 300$ was found to display ubiquitin ligase activity towards $\mathrm{p} 53$, and therefore, $\mathrm{CBP} / \mathrm{p} 300$ could also play a direct role in p53 degradation [53].

The E2F family of transcription factors play a pivotal role in regulating cell cycle progression and apoptosis [54]. In mammals, the E2F family has six different members. The best-characterised member is E2F-1 and its over-expression has been shown to be strongly associated with lung carcinogenesis [55]. The ability of E2F-1 to stimulate transcription appears to be subjected to multiple regulations including co-activation by $\mathrm{CBP} / \mathrm{p} 300$ and reversal of $\mathrm{Rb}$-mediated repression through $\mathrm{Rb}$ phosphorylation [55]. At a molecular level, the Cdk-stimulated interaction of $\mathrm{CBP} / \mathrm{p} 300$ with E2F-1 may be involved in irreversibly committing cells to cell-cycle progression [56]. Interestingly, although E2F-1 has been shown to be acetylated in vitro by both $\mathrm{p} / \mathrm{CAF}$ and $\mathrm{CBP} / \mathrm{p} 300$ at the same lysine residues, a specific role for $\mathrm{p} / \mathrm{CAF}$ in acetylation-induced stabilisation of $\mathrm{E} 2 \mathrm{~F}-1$ in response to DNA damage was recently reported [57].

One of the major tasks of $\mathrm{CBP} / \mathrm{p} 300$ is the cross-coupling of distinct gene-expression programs in response to various stimuli [28]. However, CBP/p300 levels in vivo are considered stoichiometric and apparently cannot simultaneously support its various functional activities. Thus, CBP/p300 over-expression or their preferential usage by certain "hyperactive" transcription factors, or a combination of both, could contribute to unopposed cellular proliferation as well as apoptosis inhibition during lung carcinogenesis. Recently, CBP over-expression at the very early stages of respiratory epithelium carcinogenesis has been documented [28]. This observation has led to a "step-wise" model in which $\mathrm{CBP}$ over-expression accompanied by upregulation of members of the activator protein-1 (AP-1) family and a gradual downregulation of the retinoid acid receptor $\beta$ might favour lung tumour progression and proliferation [58].

This model is in accordance with clinical observations that have identified cyclin D1 over-expression, which is AP-1 dependent, as a frequent event in human lung tumours [59]. Intriguingly, recent studies have demonstrated that cyclin D1 could control transcription factor activity by directly interacting with and repressing the transactivation capacity of p300 [60]. Nevertheless, the mechanisms by which cyclin D1 regulates a variety of cellular functions are not fully understood. Another gene that merits discussion in consideration of lung carcinogenesis is cyclooxygenase-2 (COX-2). It has been shown that growth factor-induced COX-2 transcription is mediated through the Ras-MAPK signalling pathway and through subsequent activation of AP-1 [61]. COX-2 is an inducible enzyme during carcinogenesis, and many experimental and clinicopathological studies have revealed that COX-2 over-expression is associated with respiratory epithelium tumorigenesis through proliferation enhancement, apoptosis inhibition and triggering of angiogenesis [62]. In this respect, it is important to note that $\mathrm{CBP} / \mathrm{p} 300$ are the predominant co-activators in COX-2 transcriptional activation [63].

Collectively, the accumulating evidence indicates that $\mathrm{CBP} / \mathrm{p} 300$ function as general co-regulators of a variety 
of transcription factors that could have either tumour-suppressing or tumour-enhancing properties. The abundance of $\mathrm{CBP} / \mathrm{p} 300$ and the specific interaction mode between $\mathrm{CBP} / \mathrm{p} 300$ and these various factors as dictated by the specific cell type and cellular context are likely of critical importance in determining how $\mathrm{CBP} / \mathrm{p} 300$ might modulate cell physiology/pathology and regulate disease pathogenesis such as lung carcinogenesis.

\section{The potential of modulating $\mathrm{CBP} / \mathrm{p300}$ in lung cancer therapeutics}

In theory, $\mathrm{CBP} / \mathrm{p} 300$-mediated signal propagation during respiratory epithelium tumorigenesis could be modulated by diverse strategies (Figure 3). For instance, in the case when their over-expression constitutes the problem, antisense oligodeoxynucleotides and RNA interference approaches could be used to reduce their production [64, 65]. Targeting protein-protein interfaces has emerged as a promising anticancer approach, although many theoretical caveats have to be tackled [66]. Moreover, new technologies have recently emerged to selectively block the function of critical transcription factors (e.g. structure-based rational design of decoy oligonucleotides) [67].

Being one of the key enzymes involved in post-translational modifications, the acetyl-transferases $\mathrm{CBP} / \mathrm{p} 300$ hold crucial roles in the causal relationship between dysfunction of the acetylation/deacetylation equilibrium and respiratory epithelium carcinogenesis. During the last decade, a number of HDAC inhibitors have been identified that induce apoptosis in cultured tumour cells and have entered clinical testing [68]. Pharmacologic inhibition of HDACs might restore the distorted epigenetic network and have therapeutic effect throughout the carcinogenesis process. A proof of principle of this assumption was the recent approval of the HDAC inhibitor suberoylanilide hydroxamic acid for patients with progressive, persistent or recurrent forms of cutaneous T-cell lymphoma [68].

Although substantial progress has been made in the study of HDAC inhibitors, very little has been achieved in the area of acetyl-transferase inhibitors. Long before, polyamine-CoA conjugates were found to inhibit the acetyl-transferase activity of cell extracts [69]. Availability of recombinant acetyl-transferases (p300 and p/CAF) rendered it possible to synthesise and test more targeted and specific inhibitors, Lys-CoA for $\mathrm{p} 300$ and $\mathrm{H} 3-\mathrm{CoA}$ for $\mathrm{p} / \mathrm{CAF}[70]$. The major problem with these compounds was their lack of cellular permeability. In an effort to overcome this limitation, truncated derivatives were designed, synthesised and assessed as p300 inhibitors, with, however, disappointing results [71]. Two substituted derivatives that show about four-fold increased potency compared to the parental compound Lys-CoA have recently been identified and are currently being evaluated [72].

High-throughput screening of random chemical libraries for specific inhibitors of $\mathrm{CBP} / \mathrm{p} 300$ acetyl-transferase activity is another way of identifying compounds that could then be further modified by medicinal chemistry methodologies to develop drugs suitable for clinical application. Recently, the first naturally occurring acetyl-transferase inhibitor, anacardic acid, was found. This substance inhibits very effectively, in a non-competitive manner, the activity of both p300 and p/CAF [73], and it has been also shown to increase in vitro the sensitivity of tumours to radiation therapy [74]. By using this molecule as a synthon, a synthetic amine derivative of anacardic acid (CTPB) has been generated [75]. However, again cells were impermeable or poorly permeable to both anacardic acid and CTPB. Nevertheless, these and other natural products might offer valuable "probes" for identifying potential clinically effective remedies. For example, curcumin was recently shown to exert a specific inhibitory activity towards CBP/p300 [76]. The first cell permeable acetyl-transferase inhibitor has also been reported. It is garcinol, a polyisoprenylated benzophenone derivative of Garcinia indica fruit rind, and has demonstrated potent inhibitory activity towards histone acetyl-transferases (HATs) both in vitro and in vivo [77]. In addition, a series of isothiazolone-based acetyl-transferase interfering agents were recently reported as being potential small-molecular-mass inhibitors for acetyl-transferases [78].

\section{Conclusion}

Developing an integrated picture of the role of CBP/p300 in lung carcinogenesis is a challenging task that awaits further exploration. $\mathrm{CBP} / \mathrm{p} 300$ are considered multi-functional transcriptional co-activators participating in a broad spectrum of intracellular processes under normal and pathologic conditions. However, many questions remain unanswered. Further genetic and functional studies of CBP/p300 would aid at unravelling their prominent activities, thus generating new options for intervention during the formation of lung tumours.

Acetylation is a feature of active genes and its inhibition in vivo would repress majority of the genes, including those that are aberrantly expressed. Therefore, a systematic investigation of the effect of compounds targeting acetyltransferase activity on normal and cancerous cell lines is a prerequisite to define their potential utility in lung cancer therapeutics. Further modifications of these compounds in conjunction with continued research for new molecules could lead to the development of potential novel agents targeting acetyl-transferases. Since acetylation and other 
post-translational modifications (e.g. methylation, phosphorylation) are highly co-regulated and functionally interdependent, the effect of acetyl-transferase modulators should also be evaluated in this vein. The resulting information could be very useful to design combinatorial therapeutics targeting both HATs and other important enzymatic activities.

\section{References}

1 Chrivia JC, Kwok RP, Lamb N, Hagiwara M, Montminy MR, Goodman RH. Phosphorylated CREB binds specifically to the nuclear protein CBP. Nature 1993; 365:855-859.

2 Eckner R, Ewen ME, Newsome D, et al. Molecular cloning and functional analysis of the adenovirus E1A-associated $300-\mathrm{kD}$ protein ( $\mathrm{p} 300)$ reveals a protein with properties of a transcriptional adaptor. Genes Dev 1994; 8:869-884.

3 Janknecht $\mathrm{R}$. The versatile functions of the transcriptional coactivators $\mathrm{p} 300$ and $\mathrm{CBP}$ and their roles in disease. Histol Histopathol 2002; 17:657-668.

4 Goodman RH, Smolik S. CBP/p300 in cell growth, transformation, and development. Genes Dev 2000; 14:1553-1577.

5 Chan HM, La Thangue NB. p300/CBP proteins: HATs for transcriptional bridges and scaffolds. J Cell Sci 2001; 114:23632373.

6 Yao TP, Oh SP, Fuchs M, et al. Gene dosage-dependent embryonic development and proliferation defects in mice lacking the transcriptional integrator p300. Cell 1998; 93:361-372.

7 Oike Y, Hata A, Mamiya T, et al. Truncated CBP protein leads to classical Rubinstein-Taybi syndrome phenotypes in mice: implications for a dominant-negative mechanism. Hum Mol Genet 1999; 8:387-396.

8 Johannessen M, Delghandi MP, Moens U. What turns CREB on? Cell Signal 2004; 16:1211-1227.

9 Petrij F, Giles RH, Dauwerse HG, et al. Rubinstein-Taybi syndrome caused by mutations in the transcriptional co-activator CBP. Nature 1995; 376:348-351.

10 Petrij F, Dorsman JC, Dauwerse HG, et al. Rubinstein-Taybi syndrome caused by a de novo reciprocal translocation $\mathrm{t}(2 ; 16)(\mathrm{q} 36.3$; p13.3). Am J Med Genet 2000; 92:47-52.

11 Iyer NG, Ozdag H, Caldas C. p300/CBP and cancer. Oncogene 2004; 23:4225-4231.

12 Ionov Y, Nowak N, Perucho M, Markowitz S, Cowell JK. Manipulation of nonsense mediated decay identifies gene mutations in colon cancer cells with microsatellite instability. Oncogene 2004; 23:639-645.

13 Shigeno K, Yoshida H, Pan L, et al. Disease-related potential of mutations in transcriptional cofactors CREB-binding protein and p300 in leukemias. Cancer Lett 2004; 213:11-20.

14 Merika M, Williams AJ, Chen G, Collins T, Thanos D. Recruitment of $\mathrm{CBP} / \mathrm{p} 300$ by the IFN beta enhanceosome is required for synergistic activation of transcription. Mol Cell 1998; 1:277287.

15 Konstantinopoulos PA, Papavassiliou AG. Chromatin-modulating agents as epigenetic anticancer drugs - 'the die is cast'. Drug Discov Today 2006; 11:91-93.

16 Allard S, Masson JY, Cote J. Chromatin remodeling and the maintenance of genome integrity. Biochim Biophys Acta 2004;
1677:158-164.

17 Manning ET, Ikehara T, Ito T, Kadonaga JT, Kraus WL. p300 forms a stable, template-committed complex with chromatin: role for the bromodomain. Mol Cell Biol 2001; 21:3876-3887.

18 Shikama N, Chan HM, Krstic-Demonacos M, et al. Functional interaction between nucleosome assembly proteins and p300/ CREB-binding protein family coactivators. Mol Cell Biol 2000; 20:8933-8943.

19 Kalkhoven E. CBP and p300: HATs for different occasions. Biochem Pharmacol 2004; 68:1145-1155.

20 Fu M, Wang C, Zhang X, Pestell RG. Acetylation of nuclear receptors in cellular growth and apoptosis. Biochem Pharmacol 2004; 68:1199-1208.

21 Nadiminty N, Lou W, Lee SO, Lin X, Trump DL, Gao AC. Stat3 activation of NF- $\{$ kappa $\} \mathrm{B}$ p100 processing involves CBP/p300mediated acetylation. Proc Natl Acad Sci USA 2006; 103:72647269.

22 Ryan CM, Harries JC, Kindle KB, Collins HM, Heery DM. Functional interaction of CREB binding protein (CBP) with nuclear transport proteins and modulation by HDAC inhibitors. Cell Cycle 2006; 5:2146-2152.

23 Debes JD, Sebo TJ, Heemers HV, et al. p300 modulates nuclear morphology in prostate cancer. Cancer Res 2005; 65:708-712.

24 Muth V, Nadaud S, Grummt I, Voit R. Acetylation of TAF(I)68, a subunit of TIF-IB/SL1, activates RNA polymerase I transcription. EMBO J 2001; 20:1353-1362.

25 Ogryzko VV, Kotani T, Zhang X, et al. Histone-like TAFs within the PCAF histone acetylase complex. Cell 1998; 94:35-44.

26 Vandel L, Trouche D. Physical association between the histone acetyl transferase CBP and a histone methyl transferase. EMBO Rep 2001; 2:21-26.

27 Kamei Y, Xu L, Heinzel T, et al. A CBP integrator complex mediates transcriptional activation and AP-1 inhibition by nuclear receptors. Cell 1996; 85:403-414.

28 Karamouzis MV, Papadas T, Varakis I, Sotiropoulou-Bonikou G, Papavassiliou AG. Induction of the CBP transcriptional coactivator early during laryngeal carcinogenesis. J Cancer Res Clin Oncol 2002; 128:135-140.

29 Arany Z, Newsome D, Oldread E, Livingston DM, Eckner R. A family of transcriptional adaptor proteins targeted by the E1A oncoprotein. Nature 1995; 374:81-84.

30 Patel D, Huang SM, Baglia LA, McCance DJ. The E6 protein of human papillomavirus type 16 binds to and inhibits co-activation by CBP and p300. EMBO J 1999; 18:5061-5072.

31 Ait-Si-Ali S, Carlisi D, Ramirez S, et al. Phosphorylation by p44 MAP kinase/ERK1 stimulates CBP histone acetyl transferase activity in vitro. Biochem Biophys Res Commun 1999; 262:157162.

32 Huang WC, Chen CC. Akt phosphorylation of p300 at Ser-1834 is essential for its histone acetyltransferase and transcriptional activity. Mol Cell Biol 2005; 25:6592-6602.

33 Chevillard-Briet M, Trouche D, Vandel L. Control of CBP co-activating activity by arginine methylation. EMBO J 2002; 21:5457-5466.

34 Girdwood D, Bumpass D, Vaughan OA, et al. P300 transcriptional repression is mediated by SUMO modification. Mol Cell 2003; 11:1043-1054.

35 Thompson PR, Wang D, Wang L, et al. Regulation of the p300 HAT domain via a novel activation loop. Nat Struct Mol Biol 
2004; 11:308-315.

36 Qiu Y, Zhao Y, Becker M, et al. HDAC1 acetylation is linked to progressive modulation of steroid receptor-induced gene transcription. Mol Cell 2006; 22:669-679.

37 Thomas MC, Chiang CM. E6 oncoprotein represses p53-dependent gene activation via inhibition of protein acetylation independently of inducing p53 degradation. Mol Cell 2005; 17:251-264.

38 Black JC, Choi JE, Lombardo SR, Carey M. A mechanism for coordinating chromatin modification and preinitiation complex assembly. Mol Cell 2006; 23:809-818.

39 Guermah M, Palhan VB, Tackett AJ, Chait BT, Roeder RG. Synergistic functions of SII and p300 in productive activator-dependent transcription of chromatin templates. Cell 2006; 125:275-286.

40 Ozdag H, Batley SJ, Forsti A, et al. Mutation analysis of CBP and PCAF reveals rare inactivating mutations in cancer cell lines but not in primary tumours. Br J Cancer 2002; 87:1162-1165.

41 Panani AD, Roussos C. Cytogenetic and molecular aspects of lung cancer. Cancer Lett 2006; 239:1-9.

42 Kishimoto M, Kohno T, Okudela K, et al. Mutations and deletions of the CBP gene in human lung cancer. Clin Cancer Res 2005; 11:512-519.

43 Gayther SA, Batley SJ, Linger L, et al. Mutations truncating the EP300 acetylase in human cancers. Nat Genet 2000; 24:300303.

44 Suganuma T, Kawabata M, Ohshima T, Ikeda MA. Growth suppression of human carcinoma cells by reintroduction of the $\mathrm{p} 300$ coactivator. Proc Natl Acad Sci USA 2002; 99:13073-13078.

45 Turnell AS, Stewart GS, Grand RJ, et al. The APC/C and CBP/ p300 cooperate to regulate transcription and cell-cycle progression. Nature 2005; 438:690-695.

46 Turnell AS, Mymryk JS. Roles for the coactivators CBP and p300 and the APC/C E3 ubiquitin ligase in E1A-dependent cell transformation. Br J Cancer 2006; 95:555-560.

47 Coutts AS, La Thangue NB. The p53 response: emerging levels of co-factor complexity. Biochem Biophys Res Commun 2005; 331:778-785.

48 Sun Y. p53 and its downstream proteins as molecular targets of cancer. Mol Carcinog 2006; 45:409-415.

49 Livengood JA, Scoggin KE, Van Orden K, et al. p53 transcriptional activity is mediated through the SRC1-interacting domain of CBP/p300. J Biol Chem 2002; 277:9054-9061.

50 Demarest SJ, Martinez-Yamout M, Chung J, et al. Mutual synergistic folding in recruitment of $\mathrm{CBP} / \mathrm{p} 300$ by p160 nuclear receptor coactivators. Nature 2002; 415:549-553.

51 Ito A, Lai CH, Zhao X, et al. p300/CBP-mediated p53 acetylation is commonly induced by $\mathrm{p} 53$-activating agents and inhibited by MDM2. EMBO J 2001; 20:1331-1340.

52 Grossman SR, Perez M, Kung AL, et al. p300/MDM2 complexes participate in MDM2-mediated p53 degradation. Mol Cell 1998; 2:405-415.

53 Grossman SR, Deato ME, Brignone C, et al. Polyubiquitination of p53 by a ubiquitin ligase activity of p300. Science 2003; 300:342-344.

54 Tsantoulis PK, Gorgoulis VG. Involvement of E2F transcription factor family in cancer. Eur J Cancer 2005; 41:2403-2414.

55 Gorgoulis VG, Zacharatos P, Mariatos G, et al. Transcription factor E2F-1 acts as a growth-promoting factor and is associ- ated with adverse prognosis in non-small cell lung carcinomas. J Pathol 2002; 198:142-156.

56 Major ML, Lepe R, Costa RH. Forkhead box M1B transcriptional activity requires binding of $\mathrm{Cdk}$-cyclin complexes for phosphorylation-dependent recruitment of $\mathrm{p} 300 / \mathrm{CBP}$ coactivators. Mol Cell Biol 2004; 24:2649-2661.

57 Ianari A, Gallo R, Palma M, Alesse E, Gulino A. Specific role for p300/CREB-binding protein-associated factor activity in E2F1 stabilization in response to DNA damage. J Biol Chem 2004; 279:30830-30835.

58 Karamouzis MV, Papavassiliou AG. Retinoid receptor cross-talk in respiratory epithelium cancer chemoprevention. Trends Mol Med 2005; 11:10-16.

$59 \mathrm{Fu}$ M, Wang C, Li Z, Sakamaki T, Pestell RG. Minireview. Cyclin D1: normal and abnormal functions. Endocrinology 2004; 145:5439-5447.

$60 \mathrm{Fu}$ M, Wang C, Rao M, et al. Cyclin D1 represses p300 transactivation through a cyclin-dependent kinase-independent mechanism. J Biol Chem 2005; 280:29728-29742.

61 Chen LC, Chen BK, Chang JM, Chang WC. Essential role of c-Jun induction and coactivator p300 in epidermal growth factor-induced gene expression of cyclooxygenase- 2 in human epidermoid carcinoma A431 cells. Biochim Biophys Acta 2004; 1683:38-48.

62 Karamouzis MV, Papavassiliou AG. COX-2 inhibition in cancer therapeutics: a field of controversy or a magic bullet? Expert Opin Invest Drugs 2004; 13:359-372.

63 Karamouzis MV, Sotiropoulou-Bonikou G, Vandoros G, Varakis I, Papavassiliou AG. Retinoid-X-receptor alpha (RXRalpha) expression during laryngeal carcinogenesis: detrimental or beneficial event? Cancer Lett 2003; 199:175-183.

64 Wacheck V, Zangemeister-Wittke U. Antisense molecules for targeted cancer therapy. Crit Rev Oncol Hematol 2006; 59:6573.

65 Schlee M, Hornung V, Hartmann G. siRNA and isRNA: two edges of one sword. Mol Ther 2006; 14:463-470.

66 Gonzalez-Ruiz D, Gohlke H. Targeting protein-protein interactions with small molecules: challenges and perspectives for computational binding epitope detection and ligand finding. Curr Med Chem 2006; 13:2607-2625.

67 Leong PL, Andrews GA, Johnson DE, et al. Targeted inhibition of Stat3 with a decoy oligonucleotide abrogates head and neck cancer cell growth. Proc Natl Acad Sci USA 2003; 100:41384143.

68 Bolden JE, Peart MJ, Johnstone RW. Anticancer activities of histone deacetylase inhibitors. Nat Rev Drug Discov 2006; 5:769-784.

69 Cullis PM, Wolfenden R, Cousens LS, Alberts BM. Inhibition of histone acetylation by $N$-[2-( $S$-coenzyme A)acetyl] spermidine amide, a multisubstrate analog. J Biol Chem 1982; 257:1216512169.

70 Lau OD, Kundu TK, Soccio RE, et al. HATs off: selective synthetic inhibitors of the histone acetyltransferases p300 and PCAF. Mol Cell 2000; 5:589-595.

71 Cebrat M, Kim CM, Thompson PR, Daugherty M, Cole PA. Synthesis and analysis of potential prodrugs of coenzyme A analogues for the inhibition of the histone acetyltransferase p300. Bioorg Med Chem 2003; 11:3307-3313.

72 Sagar V, Zheng W, Thompson PR, Cole PA. Bisubstrate analogue 
structure-activity relationships for $\mathrm{p} 300$ histone acetyltransferase inhibitors. Bioorg Med Chem 2004; 12:3383-3390.

73 Balasubramanyam K, Swaminathan V, Ranganathan A, Kundu TK. Small molecule modulators of histone acetyltransferase p300. J Biol Chem 2003; 278:19134-19140.

74 Sun Y, Jiang X, Chen S, Price BD. Inhibition of histone acetyltransferase activity by anacardic acid sensitizes tumor cells to ionizing radiation. FEBS Lett 2006; 580:4353-4356.

75 Varier RA, Swaminathan V, Balasubramanyam K, Kundu TK. Implications of small molecule activators and inhibitors of histone acetyltransferases in chromatin therapy. Biochem Pharmacol 2004; 68:1215-1220.
76 Balasubramanyam K, Varier RA, Altaf M, et al. Curcumin, a novel p300/CREB-binding protein-specific inhibitor of acetyltransferase, represses the acetylation of histone/non-histone proteins and histone acetyltransferase-dependent chromatin transcription. J Biol Chem 2004; 279:51163-51171.

77 Balasubramanyam K, Altaf M, Varier RA, et al. Polyisoprenylated benzophenone, garcinol, a natural histone acetyltransferase inhibitor, represses chromatin transcription and alters global gene expression. J Biol Chem 2004; 279:33716-33726.

78 Stimson L, Rowlands MG, Newbatt YM, et al. Isothiazolones as inhibitors of PCAF and p300 histone acetyltransferase activity. Mol Cancer Ther 2005; 4:1521-1532. 